Cinémas

Revue d'études cinématographiques

Journal of Film Studies

\title{
Planes Crazy: Transformations of Pictorial Space in 1930s Cartoons
}

\section{Donald Crafton}

Volume 15, numéro 2-3, printemps 2005

Cinélekta 5

URI : https://id.erudit.org/iderudit/012324ar

Aller au sommaire du numéro

\section{Éditeur(s)}

Cinémas

ISSN

1181-6945 (imprimé)

1705-6500 (numérique)

Découvrir la revue

Citer cet article

Crafton, D. (2005). Planes Crazy: Transformations of Pictorial Space in 1930s Cartoons. Cinémas, 15(2-3), 147-180.

\section{Résumé de l'article}

À regarder les courts métrages qu'ont produits les studios Disney durant les années 1930, il appert que la façon de penser la représentation de l'espace a beaucoup évolué au cours de cette décennie. À l'époque, les grands studios cherchaient tous à améliorer l'illusion de la troisième dimension dans la composition des dessins. L'intention était peut-être de produire des courts métrages qui, plutôt que de contraster avec les longs métrages aux côtés desquels ils figuraient dans les programmes, fonctionneraient selon des codes visuels similaires. Le présent article s'attarde aux innovations dans la représentation de l'espace ainsi qu'aux usages de nouvelles techniques dans les films des studios Disney et des studios concurrents. 


\title{
Planes Crazy: Transformations of Pictorial Space in 1930s Cartoons
}

\author{
Donald Crafton
}

\section{RÉSUMÉ}

À regarder les courts métrages qu'ont produits les studios Disney durant les années 1930, il appert que la façon de penser la représentation de l'espace a beaucoup évolué au cours de cette décennie. À l'époque, les grands studios cherchaient tous à améliorer l'illusion de la troisième dimension dans la composition des dessins. L'intention était peut-être de produire des courts métrages qui, plutôt que de contraster avec les longs métrages aux côtés desquels ils figuraient dans les programmes, fonctionneraient selon des codes visuels similaires. Le présent article s'attarde aux innovations dans la représentation de l'espace ainsi qu'aux usages de nouvelles techniques dans les films des studios Disney et des studios concurrents.

\begin{abstract}
It is apparent from viewing the short films produced by the Disney studio in the 1930s that the concepts of pictorial space changed dramatically during the decade. All the major studios experimented with increasing the three-dimensionality of their compositions. The motivation may have been to produce films that complemented, rather than contrasted with, the visual norms of the feature films they accompanied on film programs. This article looks at the spatial innovations and evidence of new techniques found in the films of Disney and competing studios.
\end{abstract}


Surface, volume, density and weight are not optical phenomena. Man first learned about them between his finger and the hollow of his palm. He does not measure space with his eyes but with his hands and feet. The sense of touch fills nature with mysterious forces. Without it, nature is like the pleasant landscapes of the magic lantern, slight, flat and chimerical.

Focillon 1989 (pp. 162-163)

Though animation studies is a relatively new discipline, it has already developed contested hermeneutics and academic controversies. Not surprisingly, many of these center around the contribution of Walt Disney, who, in the popular imagination, is to animation what Newton is to physics. In this essay I take a look at a narrowly defined period in the development of cartoon style and, while the focus unavoidably is on the Disney studio, the issues are broader. As animation entered a new phase following the transition to sound, an unmistakable shift occurred in visual style, a change that is scarcely explained by the coming of sync sound. In the most innovative studios, Disney, Fleischer and the less well known Iwerks studio, the 1920s graphic style, derived closely from the comic strip, began to grow more voluminous and tactile. Focillon's likening of touch with mystery perhaps expresses the challenge of discerning what is happening in these films.

Animation historians have been aware of these changes in the look and feel of the animated image, but the discussion has centered upon whether the animators' treatment of pictorial space was a desirable evolution or a wrong turn. The prevailing view has always been that the aesthetic transformations of the 1930s were utopian, leading to progress in cartoon art. Much of the early literature, especially that eulogizing Disney, hailed the increasing life-likeness of animation and its connection to high 
art traditions. The utopian view is epitomized by Mike Barrier (1999, p. 79), when he writes in Hollywood Cartoons: "[...] in effect, Disney asked [Jack] King and his other animators to recapitulate overnight the transition from the art of the Middle Ages to the art of the Renaissance-a transition marked in part by a shift from hard, precise, formulaic drawing to loose, exploratory sketching." It was this recapitulation that led to a Golden Age. This utopian view, not surprisingly, is the one disseminated in the Disney Company's promotional texts and DVD commentaries. In the 1930s, the studio's commercial success mirrored its nearly unanimous success with critics.

But there have been minority views that see in the increasing three-dimensionality of cartoon art a dystopian tendency. Disney was accused of losing sight of the essence of the animated art by such critics as James Agee, of The Nation. The view that Disney's transformations were steps in the wrong direction recently has been argued by Paul Wells (1998, p. 23) in Understanding Animation. "Disney's concentration on innovations in the apparatus to facilitate the animated film ultimately had the consequence... of undermining the distinctive aspects of animation itself," Wells writes. "With each technical development... Disney moved further away from the plasmatic flexibility of many of the early Silly Symphonies, and coerced the animated form into a neo-realist practice." ${ }^{1}$ This is a minority view, but the one held by many contemporary animation specialists. My interest is not so much in answering the qualitative question of which side is right, but rather in examining the crux of the controversy centering on pictorial space.

The trends during this period that have been observed by several commentators are:

- A move away from designs motivated primarily by economy-driven concerns of producing films as quickly as possible for a distributor's quota, toward designs that were developed to explore specific aesthetic solutions to problems in spatial representation.

- A move from the visual representational system of the comic strip toward the system of popular illustration found in children's books and illustrated literary "classics," such as the 
drawings and paintings that illustrated future adaptations from the Victorian booklist, such as Pinocchio and Alice in Wonderland.

- A noticeable dissatisfaction with the flat pictorial space of the animated world, visible in several crucial experiments that tested new conventions.

The animators' passion during this period seems to have been the integration of solid characters into their environment. Foreground and background become an optical continuum, not a conflict.

Disney Studio archivist David R. Smith relates that Walt Disney's interest in achieving a more convincing illusion of depth in the animation of pictorial space was piqued around 1935, when his plans for a feature-length animated film began to take shape in earnest. In fact, there were earlier experiments. A case that strikingly demonstrates the studio's interest in changing traditional representation of space in cartoons is Egyptian Melodies, one of the Silly Symphony series, released in August 1931.

Egyptian Melodies begins with a friendly spider spinning a web by the Great Sphinx. A secret door opens. The spider, in a gesture recalling the "cinema of attractions" style of direct address of early film, looks out at the viewer, utters "sh-h-h," and beckons us to follow it inside. We pass through a winding labyrinth until we reach an interior chamber deep within. This sequence was created using an astounding visual effect. The spider progresses through four dynamic spaces created by the stones out of which the Sphinx is constructed. (Their variations in coloring create a checkerboard pattern that enhances the receding lines of the linear perspective.) As we descend the stairs with the spider, we move forward into the illusionistic depth of the stairwell. We round a corner and enter a new space, a long hall. We keep moving, turn onto another stair, and the process repeats. The effect gives the impression of walking down four halls connected by flights of stairs. It is also highly kinetic, thanks to the constantly adjusting "correct" perspective lines. Players of "first-person shooter" type video games will recognize the spatial effect immediately. But instead of being rendered on 
the fly by a fast computer, the effect in Egyptian Melodies was handcrafted with drawings and cels. ${ }^{2}$

Inside the burial chamber, the spider hides in a canopic urn while five mummies dance a jig in a manner familiar to viewers of the earlier film, The Skeleton Dance. The spider (and the viewer) then observe the murals of the chamber "come to life" as figures drawn in a supposedly "Egyptian" style have a horse race, wage a battle, and finish with a grand chase. One gag is that they are bound to their two-dimensionality and cannot escape from the wall. A commander fails to follow his marching troops around a corner, violating the spatial conceit of flatness when he marches out of the frieze and into the space of the room-until he quickly realizes his mistake, retreats to two-dimensionality, and runs to catch up with his soldiers. Another gag has an attacking soldier pursuing another around a column. The assailant chucks his spear, but it misses its target and continues unseen around the back of the column, emerging to stick into the thrower's rear. Next the spider sees a long-shot scene of enormous complexity as the friezes show moving images in frantically conflicting screen directions on walls and illustrated columns-like Trajan's-with serpentine strings of interminable chases. These chaotic visions are all too much for the spider. He retraces his route through the labyrinth, exits the Sphinx, and runs screaming over the horizon.

This film gives rise to several questions. Why was the moving linear perspective of the labyrinthine space constructed with such lavish care and detail? (Part of it was even reused in the cartoon The Mad Doctor, 1933.) Was this an experiment with a new rendering process? And what is the meaning of the frieze scene at the climax of the cartoon? These are important inquiries because this film, whose pictorial space is something of an anomaly, may represent a turning point in stylistic development at Disney, when one concept of cartoon space began to give way to another.

A brief and necessarily fuzzy-edged periodization of my own devising will provide some background against which to discuss the handling of spatial problems at the Disney Studio.

The artisan period began in the studio's days as a silent cartoon short producer in the early twenties and continued 
through 1929. The studio was organized as a family business with Walt and Roy Disney as proprietors and animator Ub Iwerks and music arranger Carl Stalling as limited partners. Disney's personal involvement was divided between establishing a viable film business and supervising the films that Iwerks animated. While competition and product differentiation were always on Disney's agenda, the precarious financial status of the studio required constant vigilance.

The academy period began in 1929, around Iwerks' and Stalling's departures. Disney began expanding the animation staff to meet increasing demand for product. The studio released a film about every two weeks in 1931-1932, which appears to have been the production target (see figure 1). Disney's chief competitors included studios with contracts with major distributors - something that Disney lacked. These were the Oswald the Rabbit series (Universal; formerly produced by Disney), Paul Terry's Aesop's Fables, featuring Farmer Al Falfa (FBO/Pathé), Max and Dave Fleischer (Paramount), Harman and Ising (Warner Bros; former Disney staff), and Iwerks. The former partner, through his producer, Powers' Celebrity Pictures, had secured a deal with MGM, perhaps the most prestigious of the 1930s distributors. Each of these producers approached the potential obstacles of sound and color differently. Furthermore, each had a distinctive take on what cartoon space should be like. Because the quotidian affairs of the Disney studio are the best documented, we can tell that the animation staff was interested in the technical and artistic innovations of their counterparts at the other studios. This was not a matter of hypothetical formal influences; the animators maintained personal and professional contact through friendships and shared knowledge of the workplace. The cliquish animators in Los Angeles made it difficult to maintain trade secrets. Thus techniques and ideas moved freely through this porous intellectual community. Disney's artistic aspirations appear to have undergone a change just when Ub Iwerks began introducing clever spatial effects in his new series of films. Instead of continuing Iwerks' old studio style, Disney had the notion of teaching his animators the principles of academic art, in which neither he 
nor most of them had had formal training. Disney encouraged his animators to attend life-drawing classes at a commercial academy, the Chouinard School of the Arts (an ancestor of the California Institute of the Arts). In 1932, Disney invited a Chouinard teacher, Don Graham, to give regular classes to the staff on the studio premises; in 1934 he gave him a permanent job. The influence of this technical training is apparent in many films of the period. The figures become rounder and less "cartoony," while movements become smooth and more natural, as if pulled by gravity, thanks to the newly instituted practice of making pencil tests of the animators' drawings prior to photography. There was also an increasingly subdivided division of labor. "Inspiration artists" and draftsmen specializing in backgrounds and layouts entered the studio. Many of these newcomers brought with them European training and sensibilities. ${ }^{3}$ The academy period might be said to have ended in 1935, the year of several outstanding polished productions, and the compilation of studio knowledge into a shop manual. ${ }^{4}$

Annual Releases

\begin{tabular}{|c|c|}
\hline Year & $\begin{array}{c}\text { Number } \\
\text { of Releases }\end{array}$ \\
\hline 1928 & 4 \\
1929 & 16 \\
1930 & 19 \\
1931 & 22 \\
1932 & 22 \\
1933 & 19 \\
1934 & 17 \\
1935 & 18 \\
1936 & 17 \\
1937 & 14 \\
\hline
\end{tabular}

Figure 1. Source: Leonard Maltin, "Filmographies by Studios," Of Mice and Magic, New York, Plume, 1980, pp. 343-355.

The major studio period commenced in 1932, when Disney signed a distribution contract with United Artists and, for the 
first time, received enough advance funds to comfortably plan and execute each film. The release schedule began to taper off (from nineteen films in 1933, to fourteen in 1937), probably reflecting the effect of more time-consuming attention to details and the redirection of effort toward a feature film. The company structured itself on the prevailing studio system model, with supervising animators analogous to Hollywood's unit producers. The year 1932 also saw the release of the first three-color Technicolor production, Flowers and Trees, which garnered the studio its first Academy Award. Disney's artistic goals during the major studio period became more ambitious as he envisioned, then realized, a new kind of motion picture entertainment, the feature-length animated film. This period would end in 1941, when World War II and labor unrest disrupted the studio's normal operations. My study, however, ends in 1937, the year in which Disney's spatial representation in animated films reached a definitive stage when the studio deployed a new device, the multiplane animation system, used to film scenes in The Old Mill and Snow White and the Seven Dwarfs.

\section{Animation Technology and Pictorial Space in Cartoons}

Kristin Thompson was among the first scholars to ruminate about the influence of animation's technologically driven production requirements on film style. One component of her argument is especially pertinent here. The nearly-universal adoption of the patented Bray-Hurd cel process during the 1920s profoundly influenced not only the methods by which cartoons were manufactured-enabling streamlined efficiency in the shop-it also affected the aesthetics of the animated image. "The crucial aspect of cel animation," Thompson (1980, p. 113) writes, "is its separation of the different foreground and background layers." The result was a dimorphic pictorial space, by which I mean that different, somewhat incompatible, spatial systems were used for the background and the cel levels of the animation. It is precisely this binary rift between two planes, the segregated foreground and background, which animators sought to close in the 1930s.

The impact of this aspect of cel technology on the visual aesthetics of animation is pervasive. For one thing, it results in an 
almost irresistible tendency toward spatial shallowness in the compositions. For the most part, the animated universe of the 1920 s and early 1930s was quite flat. The cartoonists' terminology of the animation setup reflected the $2 \mathrm{D}$ conception of space; instead of theatrical directions used in feature cinematography-screen left, downstage, etc.- the cartoon lexicon used the cardinal compass points West, South, East, and North. ${ }^{5}$

\section{BACKGROUND SPACE}

In the twenties and early thirties, the composition of the background was very simple in order not to detract from the figures on the cels and to save labor. In Disney's 1920s "Alice" and "Oswald" cartoons, for example, the backgrounds were usually black line drawings suggesting the outline of a house on a horizon, a seashore, the prow of a boat, etc. Shading and other textural modulations were rare. The Mickey Mouse series during the artisan period was marked by more attention to the background, introducing shaded landscapes and interiors filled with props, such as pictures on walls. Nevertheless, the space of the first Mickey Mouse cartoons was closer to that of the comic strip panel than it was to the feature movie frame. The animators generally avoided linear perspective in their background renderings. There are obvious exceptions: trains chugging down tracks, buildings seen from the corner, sidewalks, picket fences, corridors, etc. when linear foreshortening must be used. Because they occur relatively seldom, though, lines strongly receding toward a distinct vanishing point stand out as "special," as optical accents. This is one reason why the perspective display in Egyptian Melodies is so astonishing. Was it rarely used because it takes time to render perspective accurately? Probably not; intuitively sketching foreshortened drawings can be acquired with practice. It is more likely an aesthetic choice.

Ub Iwerks had experimented with many graphic effects when he was a Disney animator, and continued to do so when supervising his own series featuring Flip the Frog. A September 1930 film, The Village Barber, shows a character walking along a wooden sidewalk. Instead of showing the planks scrolling by horizontally under foot, the perspective changes as the "camera" 
tracks along next to the character. The planks' lines bend in toward an invisible vanishing point, resulting in an illusion of 3D depth. The Cuckoo Murder Case, released a month later, has an even more ambitious scene with a tracking shot up a staircase in which the perspective on the stairs changes with each step. A January 1931 Flip the Frog film, The Village Smitty, utilizes moving deep-space receding perspective lines in a scene showing Flip's female frog friend driving up to his blacksmith shop. We see the lines on her buggy recede properly as she drives around a curve, and they continue to shift as she drives out of the frame. It is as though she had been filmed in wide angle. Though not as obvious-because his figure contains no straight lines-in most of the Flip films, when the frog turns, his body rotates in perspectivally correct space, unlike Mickey Mouse, whose head and ears stay put as flat disks, regardless of how Mickey turns his head. In 1930-1931, this attention to perspective was emerging as an Iwerks trademark.

Whether due to Iwerks' direct influence or not, animators at Disney began experimenting with similar effects. In Mickey Cuts $U_{p}$, released three months after Egyptian Melodies in November 1931, Pluto is dragging Mickey and his lawn mower West (i.e., screen left). The mower passes under a park bench as Mickey walks over it. As the "camera" "tracks" left to follow the motion, the bench's orthogonal lines (the ones drawn in perspective) change with each frame, as though it were a solid object. ${ }^{6}$ The effect is quite jolting, especially because a tree on a top cel is not similarly foreshortened. The two-dimensionality of the figures, who have no roundness, no foreshortening and who cast no shadows, contrasts markedly with this three-dimensional intrusion into their world. Apparently the animators' interest in academic drawing was not limited to figures; this sequence and the ones in Egyptian Melodies suggest the influence of learning about perspective as well. This interest may have been a vestige of Ub Iwerks' fascination with animated perspective, but Disney institutionalized his intuitive experiments. ${ }^{8}$ We also know from more than one source that pictorial space was a topic in the Chouinard School animation classes. Shamus Culhane, a "pupil” in Graham's art classes, recalled some lectures by a guest artist, Jean Charlot: 
The lectures were a delightful combination of Gallic wit and erudition. He talked a great deal about composition, and the conscious use of geometry by Renaissance painters.

During one talk he pointed out that it was normal to show several views of the same object in a painting. When this was challenged by one of the more conservative artists in the audience, he answered by saying that we naturally saw everything from two points of view, since we had two eyes. What was unnatural was our acceptance of Italian perspective, since it was based on the theory that the viewer had only one eye!

Charlot's lecture argued for a wider acceptance of the aims of modern art, and he must have been successful because there were many heated discussions in the parking lot after the meetings ended (Culhane 1981, p. 157) 9

If perspective was so rare, how did the cartoons relate the characters to their environment? Actually, "Italian" perspective is only one way of suggesting space. Another approach was to create performance clearings for the characters. One good example is The Plowboy (1929). The artist delineates a space on the background drawing by putting trees, clouds, shrubbery, the horizon, a room's ceiling, etc. around the top edge, and shrubbery, rocks, furniture on the bottom, but leaves the central space unfilled. Sometimes floor planks and foreground landscape will just stop, leaving a clean white space in the center of the frame reserved for the figures' actions. The Disney artists had long practiced this in the silent Alice cartoons, leaving a "white" area in the center of the animation background onto which the live actor portraying Alice could be superimposed. Although composing the background this way, with an open space in the center, was no longer a technical necessity, the practice lingered on, having made the transition from technique to style. Performance clearings, which emphasized the dimorphic rift between the two planes, were the predominant background technique during the artisan and academy periods, when virtually every black-and-white Disney cartoon utilized the compositional device to foreground its characters' acting. The concept 
faded away during the academy period, especially after the transition to color photography. When the later films used it, the effect tended to be diegetically motivated. In Three Orphan Kittens (1935), for example, a sequence is set on a white background that recalls the older performance clearings, but the background is a white tablecloth. Whereas the performance clearing in the artisan films was a matter of convenience, and did not attempt to disguise the break between foreground figures on cels and static backgrounds, we see the kittens on the tablecloth as cavorting in their "natural" and holistic environment.

Atmospheric (also known as aerial) perspective is a painterly technique that creates the illusion of distance by mimicking physical experience. Owing to the scattering of light by particles in the air, things in the distance are hazier than things seen closeup. The Disney artists employed the technique early on, for example, during the close-ups of Mickey and Minnie in the plane in Plane Crazy. The background is rendered in smudged pencil or charcoal to simulate the haze of aerial perspective. After Disney's new staff artists began influencing the look of the films, these painterly treatments of space became the new standard for the backgrounds. Robin Allan (1999, p. 32) observes that they "had a cultural background and an understanding of European influences which [Disney] utilized and made anew in the popular American form of cinema." In the color films of the academy/major studio period-Mickey's Fire Brigade (1935) is a marvelous example - distant scenes are rendered in violet shades, an effect visible also in Leonardo's Renaissance paintings.

Unquestionably the most astonishing spatial experiment of the academy/major studio period-and there were several contenders for this distinction in 1935-occurs in Three Orphan Kittens. The film indicates an intensification of the search for a way to impart moving perspective depth based on the principle in Egyptian Melodies, but the experiment is much more ambitious. This innovation lay in the background drawings of conventional animation. In three sequences, when the "camera" "tracks" laterally, instead of the background moving left or right behind the cels, the usual method, animator Ken Anderson 
made individual perspective drawings for each frame of moving background. In other words, in addition to redrawing the cel figures for every shot, he redrew the backgrounds as well. The first shot using the technique shows us the kittens on a highly polished tile floor. Because the viewpoint is on a level with the kittens' bodies, the tiles' edges are rendered in extremely foreshortened orthogonals. When the "tracking" shot begins, the floor lines shift very precisely, just as they would if they had been photographed "live." In other shots, a kitchen counter's edge shifts as the "lens" moves past it, and there are amazing "tracking" shots following a kitten moving from one room to another as we accurately view the dividing wall first from its right then its left side, and a vertical shift in point of view as the kitten goes up a stair. Another shot uses a top cel to show a kitten passing behind a perspectivally shifting kitchen table (not unlike the effect in Mickey Cuts $U p$ ). Though Anderson later described the experiment as disappointing ("it seemed to jitter, stutter..." [Smith 1987, p. 41]), these few shots remind modern viewers of video game imagery or computer graphics. Obviously, though, this approach to linear perspective was labor- and time-intensive, as it required at least twice as many drawings (for the background in addition to the foreground) as standard animated spatial movement. One wonders if another reason for the technique's so-called lack of success is that, as was the case in the two 1931 examples, it contrasts so much with the space of the nonperspectival scenes that the two-dimensionality in those scenes is apparent. In other words, the 3D effects stood out as "attractions" at a time when Disney was trying to integrate spectacle and narrative into a self-effacing classical whole. This was not the solution he was seeking. Three-dimensionality in the new Disney cartoon had to be all or nothing.

The facilitator of this new approach to cartoon style, based on the recollections of animators and the book he wrote in 1970, almost certainly was Don Graham. He describes, for example, the eye's movement from foreground to background in a drawing as a "passage" (derived from the art-historical technical term). "We find that this area takes on a special and magic property-it becomes an areal passage," he writes. 
This special area lies partly in the background and partly on the volume. It also lies on the picture surface, since it is a flat area. How astonishing that this area can be on the surface, back of the surface, in the background, yet on the volume, all at the same time! This is one of the true enigmas of picture structure (Graham 1970, p. 128).

We find exciting experiments in reconciling this fundamental enigma in Western visual art throughout the Disney shorts.

\section{Cel SPACE}

The other element of the dimorphic nature of cartoon production is the cel, the transparent sheet of cellulose nitrate upon which was drawn the part of the picture that would move. Throughout the early years of animation, the animators' labors and the viewers' attention were centered on the figures in motion. Backgrounds tended to be utilitarian. The synchronization of foreground and background became crucial, though, when characters had to move through space.

- Walks and runs. As early as the teens, animators had established several conventions for showing walks and runs. Obviously these were important in developing action-oriented narratives as well as maintaining visual interest in the film. The technique was completely unlike the production of a scene in a "live" film because in cartoons the character did not move- the background did. As codified in the 1920 how-to-do-it manuals like Lutz's Animated Cartoons, ${ }^{10}$ the phases of a run could be reduced to four or eight drawings, photographed in sequence, repeating the sequence for as long as desired. ${ }^{11}$ The character could remain centered in the frame with legs moving, and when the background moved, the result was somewhat the equivalent of filming a "live" actor from the side with a large background moving behind him, as was done in the silent days (cf. Teddy at the Throttle, Keystone, 1917). If the character were to appear to be moving West, then the background would have to move East. If the character was to be moving for some distance, either a very wide background would have to be drawn (as illustrated in Lutz) or a shortcut devised. Animation stands accommodated 
backgrounds in the form of oversize sheets, called 1-pans and double pans. ${ }^{12}$ The background was planned so that the extreme right and left sides would match, for example, by having a horizon line begin/end in the same position. The cinematographer would simply begin the background anew from the right when the paper ran out on the left (still assuming that the character is moving right to left). To extend the length of the run, the background pans were simply cycled over and over. One example out of dozens that might be cited is The Dog Napper (1934).

Although this system produces the desired effect of giving the impression of a character moving in a lateral direction, upon closer consideration the cycled background is spatially irrational. Its repeated scenes construct a circular space for the character. The more it walks, the more it gets to the point where it began. ${ }^{13}$ Here the binary split between cel and background becomes topographically complex. The animated world of the background is curvilinear, as though the character were circumnavigating its little globe every few strides. The strides themselves, however, are in a straight line (since, through cycling, it's the same stride over and over). Carried to its logical—or illogical—extreme, the character eventually should walk right off its round world! Such is the geography of toons. (It is this aspect of animation space that the commander and troops sequence in Egyptian Melodies mocks.)

- Planar and depth movement. The aesthetic schism between foreground and background encouraged planar movement instead of depth movement in Disney's artisan period and it is this that began to change in the major studio period.

Classical pictorial space represents the image as though the viewer is gazing at a scene through an imaginary glass window, the picture plane. Renaissance artists conceived the canvas or drawing paper in traditional Western art as a visual pyramid. The eye was the apex; the picture plane was the base. (Don Graham refers to this as the "picture box.") The action in early Disney films adheres closely to the picture plane. There are lots of planar movements (North, South, East, West) because they were accomplished with relative ease by retracing the drawings and changing only the parts that moved (such as the feet). The 
intention was to simulate typical cinematographic movements, the "tilt" (up-down), the "pan" (left-right, with a static camera, as on a tripod), and "tracking" shots (left-right or in-out with a moving camera framing the figure). (Quotation marks indicate that these are movements constructed by animation drawings, as opposed to standard film movement created by actually displacing the camera.) So the action tends to take the form of a frontal display, as on a shallow theater stage, or in a frieze-like procession.

The mummies' dance in Egyptian Melodies and the skeletons in Skeleton Dance are typical frontal displays. They retain the feel of a vaudeville dance performance, even when the setting is inside a tomb or a graveyard.

The frieze was one of the animators' most common devices. Mother Goose Melodies (1931) tells the story of Old King Cole, who marches West across the screen in a "tracking shot" until he reaches his throne. Then the "camera" "tracks" back East to encounter various Mother Goose characters in their storybook settings. In the late twenties and early thirties, the Disney artists framed their characters full figure or from the knees up (the socalled plan américain composition favored in early cinema). During the academy period, though, the artists began showing more half-figures and more facial close-ups, consistent with the more character-oriented comedy and individuation of personalities that Disney was innovating in his films, as well as an increasing simulation of feature-film cinematographic style.

One peculiar feature of planar movement in this and Disney's films is that frequently a character will streak to the left or right, before turning on a dime and racing toward the horizon. In other words, when a character changes direction, it is usually an abrupt right-angle turn from a frieze movement to a depth movement, or vice versa. In Plane Crazy, the aircraft traces L-shaped (2D) contrails as it loops through the sky. The tendency toward right-angle turns is yet another indicator of the dimorphic world of the cartoon. True diagonal movements, say, receding away from the picture plane at a 45-degree angle, were relatively rare, presumably because they were more difficult to draw in correct perspective. 
Don Graham refers to these friezes and planar movements in his discussion of the evolution of pictorial space. He notes that the Egyptians used a "shut-off" plane intentionally to limit depth in the composition.

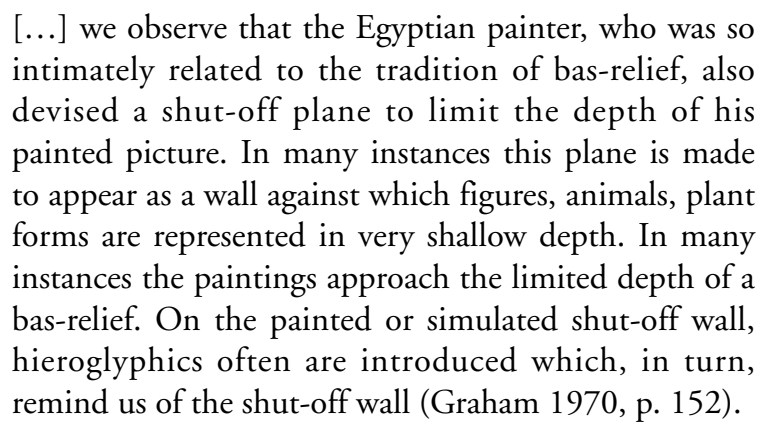

While this describes the effect seen in Egyptian Melodies, we also see something similar in a 1934 Schlesinger/Warner Bros. cartoon, Beauty and the Beast (Friz Freleng), when a picture of the Sand Man on the wallpaper in a child's room steps off the wall (the shut-off plane) into the space of the room.

Planar movement, on one hand, could be efficiently animated because, after the artist had sketched the beginning and end points of an action, the "extremes," then assistants could provide the phases in-between. Depth movement, on the other hand, was more difficult to animate because each drawing had to be completely rescaled. If a character is to recede into distance, the so-called perspective run technique, it must become progressively smaller in each drawing. Unlike lateral movements, the only way that these cels could be cycled to compensate for this extra work and extend the sequence was to have the character come back. So when characters run to or from the camera, they would often run the other way as well, accomplished by repeating the drawings in reverse order.

This technique militated against defining very deep spaces, since the distance that the character traversed was kept rather short. The reuse of cel cycles this way is one reason why the movement in early sound animation is so rhythmic. The typical 8-cel sequence repeated three times lasts one second and provides a throbbing visual tempo that synchs up perfectly with a 
musical score composed in 4:4 time. Just a couple among many further examples of perspective runs are the old tree that does one in Springtime (1929) and the ducks that fly into the distance in Autumn (1930).

Plane Crazy is one of the most spatially innovative films in Disney's early oeuvre and a showcase of most of the visual motifs in the early Disney portfolio. Not surprising, since the film was designed as the studio's show reel with which Disney hoped to land a distribution contract for his new Mickey Mouse series. The talented Iwerks, who clearly wanted to show his stuff, animated it. In the sequence in which Minnie is chasing Mickey in the runaway plane, the aircraft zigzags all around the barnyard setting, flying perpendicular to the picture plane (that is, directly towards us and away from us), and even executing diagonal flights (approaching the viewer while also flying East or West). Another recurring example of screen movement toward or away from the picture plane is a carry-over from the days of silent animation. The wide-angle depth run shows a character moving to or from the lens in wide-angle distortion, while the background rapidly recedes or approaches. It is actually a relatively easy effect because it depends on cycling both the cels and the backgrounds. The character's actions and the background repeat every second. The figure remains static and centered-except for the running feet. Meanwhile, the landscape recedes perspectivally at a brisk clip. The result is always an eyepopping attention getter.

An exceptional film that self-consciously highlights movement on the diagonal is Woodland Cafe (1937). Two bugs enter the dining room screen left and the maître d' escorts them toward their table screen right at an oblique angle. The apparent size of their fully rounded bodies correctly diminishes with each step - a remarkable animation tour de force.

A depth effect that occurs at least once in almost every Disney film of the artisan and academy periods is the aggressive wide-angle charge. A figure will suddenly loom into the "lens" of the implied camera, resulting in a simulated fisheye lens effect, and a decidedly in-your-face gesture. Spiders who swing into the "camera," grimace, and swing back, occasionally motivate these 
instances. When Minnie flies into a cow in Plane Crazy, the animal's udder and teats soar toward us in screen-filling close-up. As the plane continues to careen down the road, telephone poles loom into our view until they render the screen completely black for a couple of frames, then recede. Pilots Mickey and Minnie collide with assorted pedestrians and vehicles as they fly down the road. (Once they crash head-on into a car which, when the film is examined in slow motion, turns out to be driven by a cat that certainly looks like Felix-perhaps an early example of an animator's in-joke at the studio.) Minnie's mouth opens wide and swallows the "lens." A point-of-view shot shows us Mickey's view of the up-rushing earth as he plummets from the plane.

Other examples of the wide-angle charge are found in The Plowboy (1929), when the horse does a perspective run into the backward-tracking "camera," until it almost presses its nose into the "lens." A similarly constructed scene provides the opening shot in Pluto's Judgement [sic] Day (1935). He comes tearing out of the distance in hot pursuit of a cat and his head is shown in extreme wide angle as he rounds the curve (a near-right-angle turn) and races to the left.

The year 1935 saw several experiments using aggressive wideangle compositions. An unusual variation occurs in Mickey's Kangaroo (1935) when Pluto leans his face to the "camera" and addresses the viewer in an aside. (We hear his thoughts ["That's the last straw...”] as voice-over.) The three asides are all rendered in fisheye lens fashion. Mickey's Fire Brigade has an astonishing scene showing the mouse riding a wildly spewing fire hose. As the hose flings Mickey through the air, his body size expands and shrinks, not in the cartoony "stretch and squash" style, but anatomically proportioned according to its distance from the "camera." When the hose sprays the "lens," it takes some seconds for the water to drip away from its "surface." Also in 1935, in Three Orphan Kittens, the bold spatial experimentation continued, showing the maid's feet walking into the "lens," becoming accurately rescaled with every step. ${ }^{14}$

The aggressive wide-angle distortion effect seems to have been associated with villains and threatening creatures, such as 
the arachni-villains in Springtime (1929), Mother Goose Melodies (1931) and Woodland Cafe (1937). The lead skeleton in Skeleton Dance hops towards the camera until the jaws engulf it (black frames). Then the "camera" (and the viewer) pass through the skeletal pelvic opening (in what could be either a scatological or obstetrically based joke). The cat judge in Pluto's Judgement Day (1935) bends closer and closer to the camera until only his demonic eyes fill the screen. Similarly, the bats in The Old Mill glide toward us, their fangs becoming brief abstract filigrees. The visual shock created by this intrusive disruption caused by shattering the picture plane is a correlative for these figures' physical threat. In all cases the wide-angle charge is supposed to surprise the viewer; in many case it is supposed to be downright scary.

- Fielding. The animation camera in carefully calibrated steps could move up and down on its vertical axis above the frame containing the cels and background to achieve the effect of a tracking shot moving into or out of depth. The term used was fielding, referring to the camera's field of view and to the motion effect that results from repositioning the camera during frame-by-frame photography. Optically, the effect is more like a zoom because, unlike a true tracking shot, there is no parallax shift. That is, as the picture is reframed in a live-action tracking shot, nearer objects are seen as larger and they move across our field of vision faster than distant objects. In the animation fielding shot, the pictorial space remains resolutely planar. Scrutinizing these reframing shots reveals them to be what they are: the camera moving closer or farther from flat drawings, not through $3 \mathrm{D}$ space. ${ }^{15}$ One way to correct this "defect" is to place part of the background (for example, the moon) onto top cels, and move it toward the edge of the picture as the camera "tracks" in.

Top cels are stacked cels that sometimes were used to suggest multiple depth planes. ${ }^{16}$ The simplest form just adds rain, snow, clouds etc. to a scene. Winter (1930) begins with standard streaks of falling snow. The cel cycles become apparent when the streaks begin to dance in ziggurats synchronized with the music beat. In Springtime (1929), a row of cattails moves in front of a 
stalking stork during the "tracking" shots, but the foreground moves at the same motion rate as the background sheet. As a result, there is minimal impression of depth. Summer (1930), however, is an early illustration of how the technique could make the pictorial space much deeper. A second cel is applied over the cel containing the animated figure drawings. It moves laterally along with the action, but is timed to move slightly faster than the moving background, an effect Thompson (1980, pp. 112-113) calls temporal parallax. Though still planar, a more complex space is created that sandwiches the character between two planes, establishes a middleground, and simulates a panning shot.

In the academy period, these top cel depth effects became quite elaborate. Mickey Plays Papa (1934) begins with a stormy opening scene showing the clock tower of a moonlit building. The moon is on the static background sheet. On top of it is a cel element with moving clouds that pass translucently across the moon. Then a cel with the static drawing of the building is next. Above that is a top cel with moving foreground foliage and bats that fly out of the belfry into the "camera" (wide-angle charge shot). The scene dissolves to a more distant view and a mysterious robed figure enters the picture from West as the camera refields to frame the cabin window. This unusual sequence apparently uses four layers of cels (and possibly five if the bats and foliage are on separate elements). ${ }^{17}$

Mickey's Fire Brigade has a scene framing Clarabelle the Cow through a transom in long shot as she takes a bath. In the foreground, Goofy's big head pops up, presumably using a top cel. The composition is rather like the deep focus framings in Citizen Kane. In Little Hiawatha (1937), the complex opening shot shows the title character paddling his canoe in the distance while a waterfall flows in the foreground. As Hiawatha approaches the picture plane, he makes a turn and passes West behind the waterfall. Although the shot does not utilize the multiplane camera system, clearly the spaces visualized by the animation staff were being laid out in ever-greater complexity. The Old Mill uses many top cels for its visual pyrotechnics, coordinated with the new camera to enhance three-dimensionality, as 
in the storm sequence and its scudding clouds that envelop the structure and the lightning that seems to shoot from the distance into the foreground.

- Attached Shadows. The films of the artisan and academy periods seldom had characters casting shadows. This extra drafting task would slow down the production schedule. Winter (1930) seems to poke fun at the shadowless world of early toons. The groundhog emerges from his lair to predict the end of winter. He does not see his shadow and the neighbors rejoice at the prospect of an early spring. Then the sun returns from behind the clouds and the groundhog's shadow appears. The rodent runs back into his den, slamming the door behind him. The shadow bangs on the door to gain entry. The message seems to be that shadows cause trouble.

The films of the major studio period began to acquire figures with attached shadows. In Playful Pluto (1934) the pup has a not-too-accurate but nevertheless consistent shadow in every scene. Later, Little Hiawatha, Pluto's Quin-puplets, Woodland Cafe and The Old Mill (all 1937) rely on shadows to anchor the characters in a believable $3 \mathrm{D}$ space. These shadows are very important because they break down the division between foreground and background (the effect Graham refers to as "passage.") The cel-drawn figure is vertical, but its shadow cast on the ground is horizontal and foreshortened into depth. This implies that the character has volume and solidity and exists in a unified visual world.

- Oil and Water. One last observation about cel space concerns the ways in which the divide between foreground and background stems from the graphic media themselves. In the black-and-white films of the academy and major studio periods, the cels and backgrounds were rendered differently. Backgrounds were done in light watercolor washes to suggest aerial perspective, but also to contrast with the figures that were inked in solid lines and painted with opaque gouache or tempera. This makes the character stand out from the background, creating a poster effect without using perspective. Mickey's Kangaroo (1935) is typical. This contrasts with an elaborate color film such as Country Cousin (1936). Though the back- 
grounds are still in watercolor and the figures are painted with opaque pigments with a gum arabic binder, the figures, because of the nuances of color, tend to be more integral with the background. The end-point of this development is The Old Mill where there is little discernible difference in color treatment between foreground and background.

- Multiplane animation stands. The tendency toward increasing classicism (what Wells calls neo-realism) in Disney's pictorial space culminated in the invention of the multiplane camera that premiered in 1937. But again, other studios were experimenting with mechanical means of integrating foreground and background space. Early in 1934, Iwerks began working on a device he called the "multiple animation stand" in his workshop. Actually, the prototype was "an old Chevy [chassis] that he bought for $\$ 350 "$ (Culhane, quoted in Iwerks and Kenworthy 2001, p. 130). The device held the background and layers of cels horizontally, instead of the usual vertically arranged animation stand, and allowed spaces between the cels to create actual, not simulated, spatial depth. The multiple animation stand was used on at least three films, The Headless Horseman (October 1934), Don Quixote (November 1934), and The Valiant Tailor (ca. 1934).

The Fleischers released several cartoons utilizing a "Setback" (also known as "Turntable") process that Max Fleischer had patented (for example, Betty Boop and Grampy, in 1935, and notably, Popeye the Sailor Meets Sinbad the Sailor, in 1936). ${ }^{18}$ Instead of painted backgrounds, the Fleischer process used three-dimensional background models that could rotate on a turntable. A glass frame held the 2D animation cels in from of the machine in a horizontal configuration.

The Disney machine, patented by his engineer, William Garity, was, like the Iwerks and Fleischer models, not a camera but an animation stand. It contained six glass planes eighteen inches apart that could accommodate cels, moving and static backgrounds configured vertically in an eleven-foot tall frame. As the camera moved to and fro above the drawings, the effect of a tracking shot into/out of the scene resulted. The nearer cels' angular velocity was greater than that of far cels, and they went 
out of focus as they grew closer, producing parallax and a convincing illusion of three-dimensionality.

In their attitude toward pictorial space, there was a definite sea change in the studios, of which these space-generating machines were symptomatic. The effort to transform spatial conventions coincided with upgrading the animators' formal art training, developing multifaceted characters, and writing more ambitious stories. The Disney studio took the concept further. As with a live-action studio of the time, the idea was to have a completely systematic production design, coherent and organized at every level. This desire became concretized in the Process Lab, a secretive enclave established in the mid-1930s in the Disney studio about which little information survives. The Lab and its related Special Effects Camera Department appear to have been a sort of think-tank with the mission of innovating new screen practices and technologies. It was here that the Disney multiplane system-in several versions-was developed. ${ }^{19}$

The trend toward spatial integration is evident, though, even in films that did not use the multiplane technique. That the older planar conception of space was beginning to admit more depth can be seen clearly in a film like Clock Cleaners (1937). Donald, Goofy and Mickey venture freely in a convoluted space of gears and springs and develop their unique personalities while, and to some extent as a function of, displaying their dizzying aerobatic antics.

\section{Some Pictorial Space Motifs}

The cartoon producers of the early thirties were forced to temper artistic expression with the relentless pressure of their distribution schedule. At Disney, the Silly Symphonies were an experimental lab for new ideas and techniques, but the animators also relied on a library of conventional narrative structures and patterns of representation that they used, reused, modified, lent out and stole back until they became stylistic motifs, consistent solutions to recurring problems of film construction. Concentrating only on the conventions of pictorial space in Disney, we can identify quite a few of these motifs. 
- The carnivalesque opening shot. Starting a film (or any other artistic work) is the hardest part. Animators developed a convention that solved the problem without having to reinvent a novel opening for each film. Almost every film in the artisan and many in the academy periods begins with a shot distinguished by some extravagance. The extra labor required to produce this over-the-top visual effect is usually evident. When the opening shot ends, the camera refields, draws closer into the scene and the story begins. This is the standard opening gambit in many of Disney's films, even much later in the studio's feature productions (e.g., Peter Pan).

Plane Crazy (1928) is spatially much more ambitious than any other films of the 1928-1930 period. It begins with a barely comprehensible opening shot. The black shapes become a cow and a duck that amble through a performance clearing. Other animals are hard at work assembling Mickey's plane. A worm is popping in and out of its hole in the ground. The duck grabs it, is drawn into the worm's subterranean lair, and then pops out of another hole. The duck runs to the camera with its wide-angle distorted bill and lashing tongue filling the screen.

Following Bakhtin, I call this motif the carnivalesque opening shot because it presents a topsy-turvy version of the ordinary world (the barnyard), because it has several centers of visual interest (as in the case of a decentered three-ring circus), and because it has the air of the surreal and the grotesque (animals assembling a plane? worms attacking their predators?). The distinguishing feature of the motif is its reflexive highlighting of the excessive labor of its own creation, its assertive visual presence and its eye-appeal.

The Skeleton Dance, Disney's best-known film from the artisan period, has one of the most extravagant openings. Lightning strokes cut across the black screen and two monstrous eyes overfill the frame. As the "camera" "tracks" back, the eyes are revealed to be an owl's. Moving farther back, we see the bird silhouetted against the moon in a highly decorative vignette.

Karnival Kid (1929) is a fine example because the setting really is a carnival and is abundantly grotesque. The first frames of the film are completely black with abstract white patches. 
Gradually the outline of a black cow seen from the rear coalesces and she wafts away from the "lens," borne aloft by balloons. She drifts into the distance (diminishing constantly), and then drifts back (cel cycling). This time she fills the screen with her face and gives the viewer the "razz" (the aggressive wide-angle effect). All the while this motion is unfolding, we see the carnival in an encompassing establishing shot-tents and performers trailers in the middle ground, moving carnival rides in the distance. It is populated with dozens of tiny figures going about their frenetic carnie work, filing into tents, chasing balloons, and so on, all animated by cycled cels. The overall visual effect is one of great excitement and commotion. Such scenes required the coordination of complex motions and at least two top cels to animate the figures. The pay-off, though, is obvious. The carnivalesque opening shot immediately rivets the attention of the viewer to the scene, announces its surreal imagery (the floating cow), and entices us into the diegetic world of the film. For the viewer trying to make out all the minute actions within the scene, it's rather like studying a "Where's Waldo" drawing. (Minnie the Shimmy Dancer's trailer is indeed discernible amidst the clutter.) Other examples from the artisan period are Springtime (1929, swaying trees and flowers in long shot; one opens its petals and transforms into a stage); Night (1930, dancing cattails on top cels); Just Dogs (1932, multiple mutts raising a ruckus in a dog pound); Bugs in Love (1932) and Woodland Cafe (1937, both films opening with swarms of cycled insects). Iwerks continued the motif of the carnivalesque opening in his Flip the Frog films, notably The Village Barber (1930), in which the complete black screen is revealed to be the black stripe on Flip's barber pole.

In 1931, Disney released a particularly impressive carnivalesque opening in The Spider and the Fly. It begins with a closeup of a fly putting on ice skates. Contrary to the standard beginning that refields ("tracks") into the scene, this shot moves out to a wider view showing lots of flies skating on what appears to be a strange rink. Then the entire picture rotates 180 degrees, revealing that the "rink" is the ceiling of a country kitchen. The "camera" reframes on a jam pot and a rather conventional film ensues with the rest of the action in friezes. 
A distant encompassing view of a burning apartment house opens Mickey's Fire Brigade (1935). The many intricate movements strike the viewer as we watch occupants jump from windows, firemen climb ladders, and so on, all animated with cycled cels. Then we see Mickey speeding toward the camera in a wideangle run, while the road recedes behind him. He makes a quick right-angle turn and the action continues laterally (East). Cycled top cels add patches of smoke that whiz past in the foreground. The sequence creates a sensation of frantic drama and speed.

The most famous carnivalesque opening shot-and a landmark in animation history-is the beginning of The Old Mill, conceived as a spectacular display of the possibilities of the multiplane system. Instead of the limited spatial range of the refielding establishment shot, this sequence takes the viewer through a three-dimensionally layered environment. The distance traversed in the "tracking" and the constantly accumulating detail impresses us. First we see the mill in the distance, framed through a close-up web being tended by its spider (not unlike Egyptian Melodies). As we enter through the cobweb, a lateral procession of cows passes behind the mill, while a family of ducks swims in the rippling pond in the foreground. Nearing the base of the mill, the camera seems to pass through a chink in the wall and discloses a bluebird sitting on her nest. Then the camera "lifts" vertically to show the other inhabitants: doves, a grumpy owl who resents the viewer's intrusion, and a colony of bats. Finally, the setting sun and the brewing storm show through a crack in the boards. This sequence is at least three separate multiplane shots subtly connected with dissolves to congeal into a single smooth motion. Although the studio planned 41 of the film's 102 shots as multiplane, ${ }^{21}$ close viewing suggests that most of the midsection of The Old Mill augments the multiplane shots with conventional refielding and top cels to simulate spatial movement. Reversetracking multiplane footage returns at the end after the storm has passed, concluding as it had begun with the spider repairing its now broken web. The narrative symmetry, with its moral concerning capricious nature, rejuvenation and the circle of life, suggests a correlative with the circular windmill gears and turning blades, but also perhaps with the cycled cels and backgrounds of 
Disney's older animation techniques. In any case, the viewer is expected to savor, not the delineation of memorable protagonists, but rather the uniqueness and sublimity of these spatial transitions. A similar shot would be outstanding in any film. Perhaps a comparable scene in a live feature would be the famous long-take tracking shot through the swamp in Sunrise (1927). As in Murnau's film, the subject is a sensuous journey through a landscape measured, as Focillon might say, with the hands and feet.

Not every film used the carnivalesque opening shot. Flowers and Trees (1932), for example, does not have one. Perhaps the astonishing chromatics of the first three-strip Technicolor cartoon were carnivalesque enough. The Three Little Pigs (1933) begins with three separate openings, each showing its respective porker in long shot, then refielding for a closer view.

The carnivalesque opening shot functions like the establishing shot (also called the master shot) in a traditional feature film, setting the stage for the plot. It is significant that there was a definite change from the eye-popping abstraction of the early sound cartoons to the narrativized use of abstraction in the major studio period, when special effects had to be integrated into and motivated by the plot. Those few moments of nonobjective representation that marked the older films' beginnings had been firmly rejected by the mid-thirties.

\section{Egyptian Melodies: A Rosetta Stone?}

Antonia Lant has demonstrated that American popular culture was gripped by waves of "Egyptomania" throughout the nineteenth and early twentieth centuries. ${ }^{22}$ Disney's 1931 film predates Universal's The Mummy by a year, and comes nine years after the famous discovery of King Tut's treasure-strewn tomb. The beginning of Egyptian Melodies, with the spider-protagonist accidentally discovering the opening at the base of the Sphinx, replays - toonified, naturally_-Howard Carter's breach and descent into the burial chamber of Tut-Ankh-Amun. Inside it is not the routine dancing mummies that intrigue the modern viewer, but the journey into the crypt through the moving perspective-perfect stairs, and the moving hieroglyphic texts and murals in the shrine. Let's try a speculative reading. 
Why a spider? Unlike the gruesome eight-legged villains that appear in several Disney cartoons, this sneaker-clad character (who appeared in two other films) is friendly and personable. But it is its ability to weave a web that is highlighted when we first see it. The spider's careful work, which requires unyielding patience and many "hands" to complete, suggests that it is a personification of the animator, much as Arachne is an artist-surrogate in mythology. The web-work recapitulates the cartoonist's constant labors. This is typical of the established convention of self-figuration in cartoons, where the animator constructs performances that mirror the animation process. This symbolism may also inform the prominent position of the web-spinning spider in The Old Mill. ${ }^{23}$ As Egyptian Melodies' spider descends into the dark space of the tomb it experiences three-dimensionality hitherto unprecedented in any Disney film. It's a threatening domain; the spider narrowly avoids pitfalls and crashing masonry. Then after surviving the mummies' assault, the spider witnesses the astonishing moving friezes of the murals, the pictorial space of which calls to mind the lateral processions of characters that populate so many Silly Symphonies. When the commander's troops march around a corner and must be redrawn in perspective, they resist walking on the diagonal, much as Disney's characters shun oblique movements in space. The hieroglyphic characters trapped in the pictorial space of the columns spend their existence running in a circular world, not unlike the cartoon characters that, thanks to cycled backgrounds, are condemned to their curvilinear worlds. Why do the streaming friezes of animated figures make the spider's brain spin (indicated by the rotating POV shot) and provoke its flight from the crypt? Mind reading is always risky, especially the toon mind, but could it be that experiencing these binary visual extremes - the enveloping moving perspective of the stairs and the relentless marching of the friezes - have triggered a crisis of animation representation in which questioning the existing conventions of pictorial space causes a break down? Overwhelmed and trapped between two competing representational systems, the spider-animator goes planes crazy!

The pictorial panic reaction in Egyptian Melodies recalls the art-historical distinction between haptical and optical modes of 
spatial representation as originally articulated by early twentieth-century art historians. Influenced by developing perceptual psychology, the concept of the haptic was evoked to distinguish the flat space of Egyptian art (said to rely on close-up touch and tactility) from the optical space of the Renaissance. ${ }^{24}$ Artists of antiquity understood spaces and the objects within by touching them and moving around them, not by seeing them at a distance. This describes the mode of spatial construction in Disney's artisan period. Spatial relationships were mainly represented by opaque objects occluding the background and each other, not objects casting shadows or moving in a unified perspective. Space is intuitive, rather than plotted by rulers and models. The optical mode depended on vision and, as Focillon points out, led to picturing sculptural objects as chimerical surfaces. David Hockney (2001) has proposed that, beginning in the Renaissance, artists commonly used lenses, curved mirrors and proto-photographic devices to translate viewing into perspective forms. In animation, the processes that are analogous to using pre-photographic aids like the camera lucida are devices like the rotoscope and the multiplane systems. The animation artists relied to varying degrees on photographic/cinematic recordings of objects and people in motion to capture the Renaissance pictorial dimensionality they sought.

So is Egyptian Melodies a modest film treatise on art history? The intention was probably not that pretentious. It may be, though, that, under the influence of teachers like Jean Charlot and Don Graham, the studio was concocting a tongue-in-cheek parable about the ontogeny of cartoon space. The old style of graphic pictorial space represented by the haptic art of the Egyptians was flat, limited and repetitious; the optical art of unified constructed spaces and perspective verisimilitude was the new direction.

Returning to our opening opposition, we see that, as winsome as the utopian thesis is that the animators were imbibing the whole history of Western art in a few years, this theory is misleading because it implies that the artists drew flat pictorial space because they did not know how to draw better and thus had to be educated. Clearly, though, the animators had basic competence in perspective even in the artisan years. Common 
sense suggests an axiom: If you can draw Clarabelle the Cow consistently from frame to frame, you can probably draw perspective lines on a floor or box. Creating a flat or a round world was an aesthetic decision.

The dystopian thesis, that the new realism destroyed not only the verve and inventiveness of silent cartoons, but tainted postDisney animation with literalness and sentiment, is reminiscent of Rudolf Arnheim's similar claims about the films of the 1930s, which argued that technological "advancement" was really a destruction of essential cinema.

The transformations of space that I have charted are neither progressive nor regressive. They are a transition from one graphic performance of spatial representation to another kind of performance. But where should we look for the motivation of these changes?

There is the cultural context to consider. Disney's films spoke to sophisticated viewers and intelligent commentators, as well as "the masses," throughout the 1930s. The discourse of high art that the studio generated was intended to give the productions the imprimatur of quality, without sacrificing mass entertainment value. Seen as a social text, the shift to the new style in the art of Disney and the other studios was consistent with certain trends in American art in the 1930s, which rejected formal abstraction in favor of solid figural forms. I am thinking of Reginald Marsh's carnivalesque paintings and graphic arts, such as his versions of Coney Island Beach from 1934 and 1935, and of Edward Hopper's hard edge, quasi-photographic scenes of everyday life.

The changes in the conception and rendering of pictorial space in the 1930s studio cartoons from the early sound period through 1937 produced more visually complex imagery that tended to become more solid and three-dimensional. Life-like is not exactly the right descriptor; the effect is more like the uncanny import of fantastic drawings and objects from the world of popular graphic art into a live-action cinematic space. Whether cause or effect, the result of the trend toward reconciling the foreground and background worlds of animation produced a visual style that looked more like a Hollywood feature film. This mirrored the efforts of the producers, notably 
Disney, to adapt the hierarchical practices of the mainstream studio system to animated production. Hollywood form and animated content came together in the feature Snow White (1937).

After World War II, as Disney and other producers made feature-length films to rival live-action programs, the integrated conception of cartoon space dominated American animation. The famously flat and planar UPA studio style of the 1950s is the best known reaction against the prevailing Disney vision of cartoon space. Eventually, even Disney's films became flat again - as they had been in the 1920s and early 1930s. As for the haptic dimension of Disney art, that which relies on threedimensionality, visceral sensation, emotion, touch and movement: the thrill rides and audio-animatronic installations in the Disney theme parks of the future would supply plenty of that.

\section{University of Notre Dame}

\section{NOTES}

1. "Plasmatic" was a term coined by Soviet filmmaker Eisenstein to describe the boundless world of cartoons.

2. It is possible, even probable, that the effect was generated with some sort of photographic assistance, such as a rotoscope technique. But I have no evidence.

3. See Allan 1999.

4. See Barrier 1999 (p. 139).

5. The reframing indications are clearly visible as concentric rectangles drawn on storyboard sketches. See the illustrations in Finch 1982 (pp. 42-44).

6. As Thompson shows, the animation camera normally does not move laterally during a panning shot, the drawings do. The camera can move up and down, however, to simulate tracking shots into and out of the space of the drawings. By the mid1930 s, these movements commonly were combined as "refielding."

7. The top cel is simply a cel with another layer of action figures on it. Sometimes part of a static background can be on a top cel to enable a character to pass behind an object, such a tree. See further discussion below.

8. Barrier (1999, p. 167) observes: "There are glimpses throughout the Flip series of Iwerks's technical facility, as mechanical objects move with a verisimilitude often lacking in the animation of the characters. That facility extended beyond the drawings themselves: Iwerks's animation camera could track into and out of a scene very early in the thirties, almost certainly earlier than anyone else's."

9. According to a biographical sketch, Charlot (1897-1979) taught printmaking at the Chouinard School of Art in 1933 and in 1938 (see <http://libweb.hawaii.edu/ libdept/charlotcoll/J_Charlot/charlotthompson.html>). Don Graham was fond of telling an almost identical anecdote: "Graham also liked to quip that the great weakness of Italian perspective was its limitation of the single eye's vantage point. The artist 
should instead modify and adjust drawings by imagining how objects look not just from two eyes, but from four or more. 'By seeing partly around a small object...we can extend binocular vision into a new dimension”" (quoted in Neupert 1999, p. 80).

10. See Lutz 1920.

11. See Lutz's diagram reproduced in Crafton 1993 (p. 203). The eight-drawing module was based on silent film projection speed, which was approximately sixteen frames per second. It was assumed that each drawing would be shot twice ("on the twos") to save the animator the effort of making sixteen drawings for each second on the screen. After the conversion to sound, according to Shamus Culhane (1981, p. 156), the Disney studio normally used 12-frame modules, shooting each drawing twice. When especially smooth motion was desired, 20-24 drawings would be made for each second.

12. For a useful online discussion of the physical properties of cels and background art, go to $<$ http://www.vintageip.com/Term.html\#PROD $>$.

13. The Fleischer studio's "setback" alternative eliminated the repetitive drawing while making the background more three dimensional and "photographic." Essentially this was a sort of Lazy Susan. A turntable on which miniature sets were constructed was set behind the cels. When photographed, the figures seemed to move across the relief background (which was turned a little with each exposure). Just like the traditional cycled paper backgrounds, though, the impression of a curved world was even more noticeable-because it literally was curved. For more info, see Maltin 1980 (pp. 339-341).

14. This shot is a little "too perfect." I have no evidence, but intuitively I suspect the use of rotoscoping to guide the animators. This of course opens the possibility that the moving perspective lines in the kitten-on-the-floor sequences (as well as those in Egyptian Melodies) might also be based on rotoscoped footage. (For the use of rotoscoping at Disney, see Culhane 1981, pp. 158-159.)

15. Smith $(1987$, p. 39$)$ describes the problem: “... if the camera simply moved toward a single background as, say, toward a cabin, the cabin would naturally become larger as he approached, but so would the moon painted above the cabin. Audiences were quick to notice these inconsistencies and it did create damage to the illusion of reality that Walt was trying to create."

16. They were also used, for example, to add effects like speed lines and lip movements.

17. The cellulose nitrate cels had a yellow color, which became more apparent when layered. The maximum number of top cels used was usually two or three (see <http://www.vintageip.com/Term.html\#PROD>).

18. See Lenburg 1983 (pp. 36, 201). The patent was filed in 1933 and granted in 1936. For an illustration of the setback machine from the application, see $<$ http://users.bestweb.net/-mentzerm/popeye.htm>. The simultaneous innovation of these machines for creating cartoon depth demonstrates: 1) the fiercely competitive nature of the animation marketplace in the 1930s, and 2) that Disney was not alone in his quest for three-dimensional pictorial space.

19. See Canemaker 1996.

20. The "raspberries," in American slang of the 1920s, was the gesture of sticking out one's tongue and blowing in order to produce a flatulent sound. It was considered offensive until eventually supplanted by the gesture of energetically exhibiting one's middle finger.

21. See Smith 1987 (p. 47).

22. See Lant 1997.

23. There is a crucial difference between the two spiders' performances. The one in Egyptian Melodies becomes the protagonist of the story. The spider in The Old Mill, 
however, is a like a repoussoir figure in classical art, such as a person on the edge of the painting who intercedes for the spectator by being both in the picture and outside of it (like portraits of "real" donors who point toward the central allegorical scene).

24. See Lant 1995. The origins of the haptic/optic dyad derive from nineteenth-century psychologies of perception and their aesthetic ramifications (Wundt, Vischer, Riegl, et al.).

\section{BIBLIOGRAPHICAL REFERENCES}

Allan 1999: Robin Allan, Walt Disney and Europe: European Influences on the Animated Feature Films of Walt Disney, Bloomington, Indiana University Press, 1999.

Barrier 1999: Mike Barrier, Hollywood Cartoons: American Animation in Its Golden Age, New York, Oxford University Press, 1999.

Canemaker 1982: John Canemaker, Treasures of Disney Animation Art, New York, Abbeville Press, 1982.

Canemaker 1996: John Canemaker, "Secrets of Disney's Visual Effects: The Schultheis Notebooks," Print, Vol. 50, no. 2, 1996.

Crafton 1993: Donald Crafton, Before Mickey: The Animated Film, 1898-1928, Chicago, University of Chicago Press, 1993.

Culhane 1981: Shamus Culhane, Talking Animals and Other People, New York, St. Martin's Press, 1981.

Finch 1995: Christopher Finch, The Art of Walt Disney: From Mickey Mouse to the Magic Kingdoms, New York, Abrams, 1995.

Focillon 1989: Henri Focillon, The Life of Forms in Art [1934], London, Zone, 1989.

Graham 1970: Donald W. Graham, Composing Pictures: Still and Moving, New York, Van Nostrand Reinhold Company, 1970.

Hockney 2001: David Hockney, Secret Knowledge: Rediscovering the Lost Techniques of the Old Masters, New York, Viking Penguin, 2001.

Iwerks and Kenworthy 2001: Leslie Iwerks and John Kenworthy, The Hand Behind the Mouse, New York, Disney Editions, 2001.

Lant 1995: Antonia Lant, "Haptical Cinema," October, no. 74, 1995, pp. 45-73.

Lant 1997: Antonia Lant, "The Curse of the Pharaoh, or How Cinema Contracted Egyptomania," in Matthew Bernstein and Gaylyn Studlar (eds.), Visions of the East: Orientalism in Film, New Brunswick, Rutgers University Press, 1997, pp. 69-98.

Lenburg 1983: Jeff Lenburg, The Great Cartoon Directors, Jefferson/London, McFarland, 1983.

Lutz 1920: Edwin G. Lutz, Animated Cartoons: How They Are Made, Their Origin and Development, New York, Scribner's, 1920.

Maltin 1980: Leonard Maltin, "Filmographies by Studios," Of Mice and Magic, New York, Plume, 1980, pp. 343-355.

Neupert 1999: Richard Neupert, "Colour, Lines, and Nudes: Teaching Disney's Animators,” Film History, Vol. 11, no. 1, 1999.

Smith 1987: David R. Smith, "New Dimensions-Beginnings of the Disney Multiplane Camera," in Charles Solomon (ed.), The Art of the Animated Image, Los Angeles, American Film Institute, 1987.

Thompson 1980: Kristin Thompson, "Implications of the Cel Animation Technique," in Teresa de Lauretis and Stephen Heath (eds.), The Cinematic Apparatus, New York, St. Martin’s Press, 1980. 